\title{
Two cases of left-sided and concomitant right-sided endocarditis: potential pathways of spreading
}

\author{
P. M. van der Zee • P. F. M. M. van Bergen • \\ P. Dekkers • R. B. A. van den Brink
}

Published online: 29 September 2011

(C) The Author(s) 2011. This article is published with open access at Springerlink.com

\section{Introduction}

Infective endocarditis involving the tricuspid valve is an uncommon disease. In most cases, it is associated with intravenous drug use [1] or the presence of a foreign body such as a haemodialysis catheter [2] or a pacemaker lead close to the tricuspid valve [3]. We describe two cases of leftsided endocarditis and concomitant right-sided endocarditis, without the aforementioned circumstances.

\section{Case report}

\section{Case 1}

An 80-year-old man with a history of hypertension, ischaemic cerebrovascular accident and bio-prosthetic aortic valve replacement because of symptomatic aortic stenosis two months before admission (sutureless Perceval Sorin) presented to the hospital with fever. On clinical examination the patient was not dyspnoeic; his blood pressure was $110 / 70 \mathrm{mmHg}$. The sternotomy scar appeared normal. On cardiac auscultation heart sounds were normal and a short grade II/VI ejection murmur was heard at the

P. M. van der Zee $(\bowtie) \cdot$ R. B. A. van den Brink

Department of Cardiology, Academic Medical Center,

Room B2-223, Meibergdreef 9,

1105 AZ Amsterdam, the Netherlands

e-mail: p.m.vanderzee@gmail.com

P. F. M. M. van Bergen · P. Dekkers

Department of Cardiology, Westfries Gasthuis Hoorn,

Maelsonstraat 3,

1624 NP Hoorn, the Netherlands second intercostal space at the right side of the sternum. Pulmonary auscultation was normal and there was no peripheral oedema. No stigmata of endocarditis were seen. Electrocardiography showed a sinus rhythm of 92 beats/min, and a new first-degree AV block (PQ interval: $344 \mathrm{~ms}$ ), with normal axis and QRS duration. Laboratory testing showed leucocytosis $\left(19 \times 10^{9} / \mathrm{L}\right)$, increased C-reactive protein (CRP) levels $(100 \mathrm{mg} / \mathrm{L})$, and pre-existent renal dysfunction with a creatinine level of $353 \mu \mathrm{mol} / \mathrm{L}$ and a calculated glomerular filtration rate of $<15 \mathrm{~mL} / \mathrm{min}$. On chest X-ray, a pre-existent enlargement of the heart was seen with a normal aspect of the lungs. Blood cultures were positive for coagulase-negative staphylococcus. Transoesophageal echocardiography revealed an aortic root abscess adjacent to the anterior leaflet of the mitral valve (Fig. 1a), as well as a vegetation on the tricuspid valve (Fig. 1b) The patient was treated with intravenous rifampicin and vancomycin and an operation was performed because of clinical deterioration. During surgery, extensive abscess formation and widespread vegetation made complete reconstruction impossible. The infected bioprosthesis was replaced by a mechanical valve. The patient died from multiorgan failure the next day.

\section{Case 2}

A 54-year-old man with no significant medical history and no intravenous drug use presented to our emergency department with complaints of peripheral oedema, dyspnoea, sweating and fever. On clinical examination the patient had tachypnoea. Blood pressure was 135/85 mmHg. On cardiac auscultation heart sounds were normal and he had no murmur. Pulmonary crackles were heard on both sides. Peripheral oedema was present. A splinter haemorrhage was seen under his left index fingernail. Janeway lesions were seen on the left 


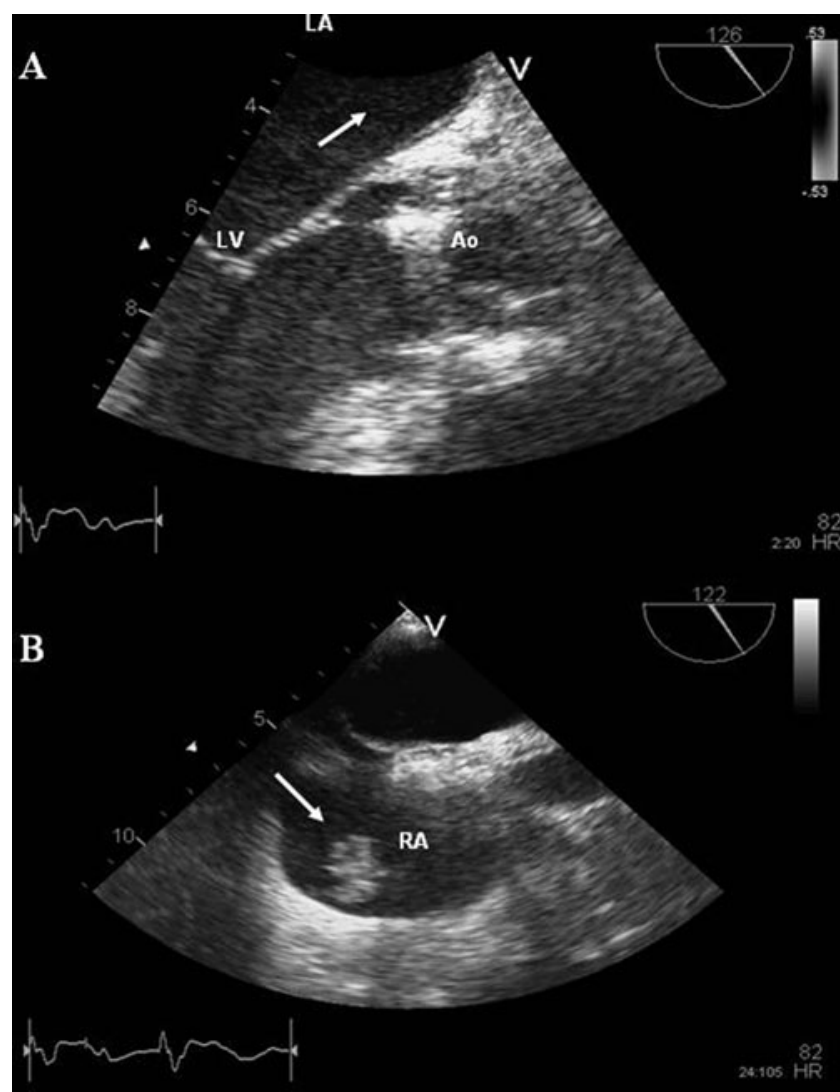

Fig. 1 Case 1. a Long-axis aortic view on transoesophageal echocardiography. The arrow indicates the para-aortic abscess. LA, left atrium. LV, left ventricle. Ao, aorta. b Bicaval view on transoesophageal echocardiography. The arrow indicates the vegetation on the tricuspid valve. RA, right atrium

index and middle fingers. Electrocardiography showed a sinus tachycardia of 138 beats/min, and no further abnormalities. Laboratory testing showed leucocytosis $\left(13 \times 10^{9} / \mathrm{L}\right)$, and an increased CRP level $(262 \mathrm{mg} / \mathrm{L})$. On chest X-ray, pulmonary oedema was seen. Blood cultures proved positive for Staphylococcus aureus. At transoesophageal echocardiography, vegetations were seen on the anterosuperior leaflet of the tricuspid valve and on the anterior leaflet of the mitral valve (Fig. 2a and b). The patient was admitted to the intensive care unit for artificial respiration and treated with a 6-week course of intravenous flucloxacillin (12 g/day). During the hospital stay, the patient also developed an arthritis of the sterno-clavicular joint, which was confirmed by a positron emission tomography-computed tomography scan. Because of development of this arthritis during antibiotic treatment, the antibiotic course was extended by 2 weeks of $6 \mathrm{~g}$ /day flucloxacillin i.v. The vegetations decreased in size and no significant valve regurgitation or intracardiac abscess developed. Antibiotic treatment was stopped and there was no relapse.

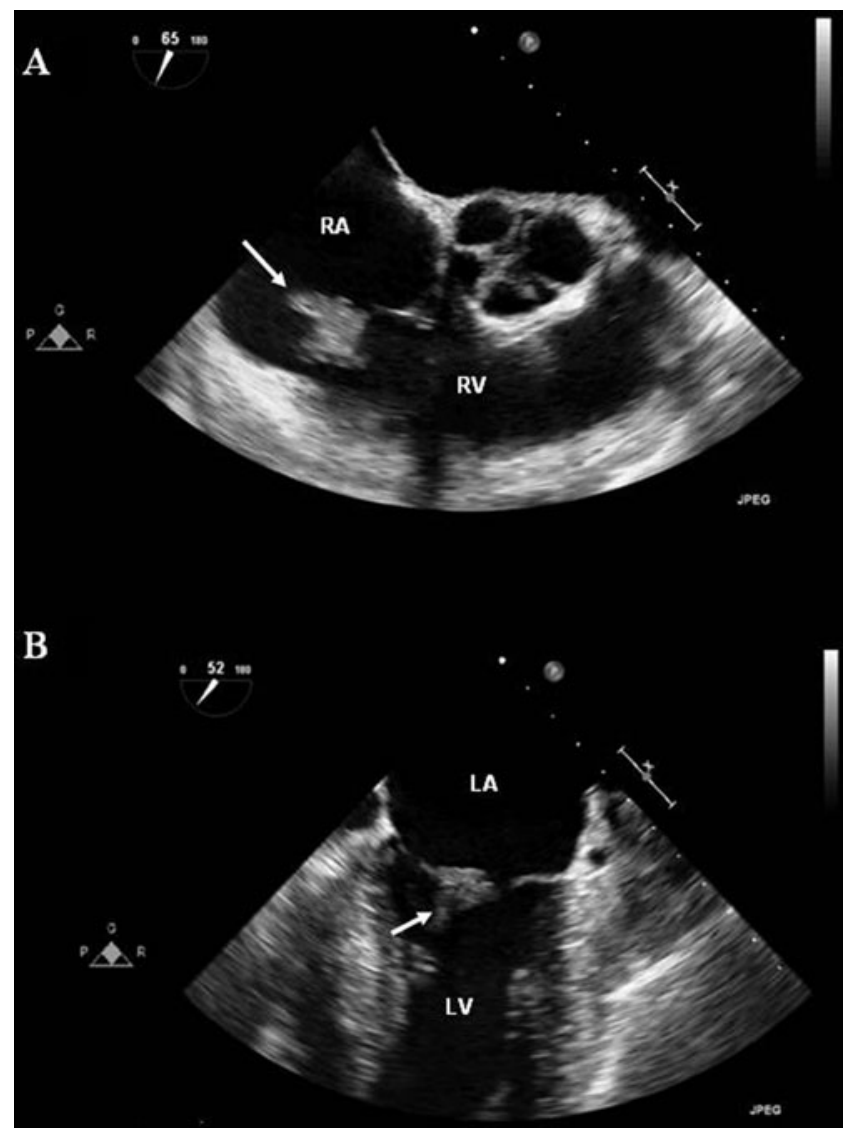

Fig. 2 Case 2. a Two-chamber view of right atrium and ventricle on transoesophageal echocardiography. The arrow indicates the vegetation on the tricuspid valve. RA, right atrium. RV, right ventricle. b Twochamber view on transoesophageal echocardiography. The arrow indicates the vegetation on the anterior leaflet of the mitral valve. LA, left atrium. LV, left ventricle

\section{Discussion}

Tricuspid involvement in endocarditis without drug abuse or presence a foreign body as a substrate for ongoing bacteraemia accounts for less than $10 \%$ of all right-sided endocarditis $[4,5]$. The most frequently found microorganism is Staphylococcus aureus $[4,6]$. Double-sided endocarditis is even more uncommon. We have found two cases in literature of double-sided endocarditis caused by a staphylococcal infection, one without any predisposing condition [7] and one with prior aortic valve replacement [4]. One other doublesided endocarditis case was caused by Salmonella enteritidis [8]. In our first case, the infection on the left side of the heart was extensive, with spread per continuitatem through the septum to the right side of the heart. However, in the second patient without abscess formation and with vegetations confined to the anterior leaflet of the mitral valve and anterosuperior leaflet of the tricuspid valve, dissemination per 
continuitatem seems unlikely. An ongoing bacteraemia with Staphylococcus aureus may have caused both mitral and tricuspid involvement in our second case, as described in literature [7]. Notably, Staphylococcus aureus is a very virulent organism that can cause endocarditis on previously normal valves.

Open Access This article is distributed under the terms of the Creative Commons Attribution Noncommercial License which permits any noncommercial use, distribution, and reproduction in any medium, provided the original author(s) and source are credited.

\section{References}

1. Mathew J, Addai T, Anand A, et al. Clinical features, site of involvement, bacteriologic findings, and outcome of infective endocarditis in intravenous drug users. Arch Intern Med. 1995;155(15):1641-8.
2. Kamalakannan D, Pai RM, Johnson LB, et al. Epidemiology and clinical outcomes of infective endocarditis in hemodialysis patients. Ann Thorac Surg. 2007;83(6):2081-6.

3. Jenkins SMM, Hawkins NM, Hogg KJ. Pacemaker endocarditis in patients with prosthetic valve replacements: case trilogy and literature review. Pacing Clin Electrophysiol. 2007;30(10):127983.

4. Revilla A, López J, Villacorta E, et al. Isolated right-sided valvular endocarditis in non-intravenous drug users. Rev Esp Cardiol. 2008;61(12):1253-9.

5. Hoen B, Alla F, Selton-Suty C, et al. Changing profile of infective endocarditis: results of a 1-year survey in France. JAMA. 2002;288 (1):75-81.

6. Nandakumar R, Raju G. Isolated tricuspid valve endocarditis in nonaddicted patients: a diagnostic challenge. Am J Med Sci. 1997;314(3):207-12.

7. Hachiro $\mathrm{Y}$, Harada $\mathrm{H}$, Baba $\mathrm{T}$, et al. Concomitant mitral and tricuspid valve infective endocarditis: report of a case. Surg Today. 2004;34(8):695-7.

8. Mutlu H, Babar J, Maggiore PR. Extensive Salmonella enteritidis endocarditis involving mitral, tricuspid valves, aortic root and right ventricular wall. J Am Soc Echocardiogr. 2009;22(2): 210.e1-3. 